\title{
Comprehensive analyses of immunoglobulin proteome and clinical variables identify biomarkers to predict mortality in patients with influenza- associated lower respiratory tract infection
}

Fei Teng

Beijing Chaoyang Hospital

Dan Wang

Beijing Proteome Research Center

Xiao-Mei Zhang

Beijing Proteome Research Center

Jian-Hua Liu

Shengjing Hospital of China Medical University

Jia-Yu Dai

Beijing Proteome Research Center

Xue Mei

Beijing Chaoyang Hospital

Yu-Dong Yin

Beijing Chaoyang Hospital

Li Gu

Beijing Chaoyang Hospital

Yu-Fei Chang

Capital Medical University Affiliated Beijing Ditan Hospital

Shan-Fang Ma

Capital Medical University Affiliated Beijing Ditan Hospital

Xian-Ting Li

Miyun Teaching Hospital

Wen-Peng Yin

Beijing Chaoyang Hospital

Xiao-Jun Yang

Beijing Huairou Hospital

Shu-Bin Guo ( $\nabla$ shubin007@yeah.net )

Beijing Chaoyang Hospital

Xiao-Bo Yu

Beijing Proteome Research Center 
Research article

Keywords: Influenza, Immunoglobulin subclass, Protein microarrays, Prediction model, Clustering analysis

Posted Date: January 15th, 2020

DOI: https://doi.org/10.21203/rs.2.20903/v1

License: (a) (i) This work is licensed under a Creative Commons Attribution 4.0 International License. Read Full License 


\section{Abstract}

Background: Influenza-associated lower respiratory tract infection (I-LRTI) brings a heavy clinical burden, and clinicians lack an effective prognostic evaluation system to control disease progression.

Methods: This was a prospective, observational study, and the endpoint was 28-day mortality. Plasma microarrays were used for quantitative analysis of immunoglobulin (Ig) and its subclasses. Prognostic factors from Ig and clinical variables in the patients with I-LRTI were identified to create a prediction model.

Results: To address this issue, we prospectively and observationally studied the difference of immunoglobulin proteome and clinical variables between survivors and non-survivals in 107 patients with influenza-associated lower respiratory tract infection (I-LRTI) selected from four hospitals affiliated to Capital Medical University. The results identified 17 variables with significant or marginally statistical differences by univariate analysis, including lymphocyte count (LY), monocytes count (MO), CD3 + CD $4+$ T-cell count, CD3 + CD8 + T-cell count, IgA, IgA1, IgG2, IgG4, CRP, PCT, D-dimer, oxygenation index, glycosylated hemoglobin, lactic acid (LAC), base excess of blood, lactic dehydrogenase, and ahydroxybutyrate dehydrogenase. Furthermore, we analyzed the correlations of all the variables by hierarchical clustering analysis in which different functional modules were formed between survival and non-survival groups that are associated with the immunity and severe infection. At last, we built a prediction model with nine variables (D-dimer, days from onset to ED, IgA, IgG2, LAC, LY, MO, Staphylococcus aureus co-infection and age), with which the AUC value of 0.810 (95\% $\mathrm{Cl} 0.755-0.839)$ was achieved with the evaluation of LOO cross validation. The predictive model was further validated by disease severity evaluation.

Conclusion: Lethal bacterial (especially S. aureus ) co-infection was associated with cellular immunity, oxygenation index, $\mathrm{HbA} 1 \mathrm{C}$ and age. The combined prediction model with D-dimer, Days from onset to ED, IgA, IgG2, LAC, LY, MO, S.aureus co-infection and age demonstrate the predictive mortality powerfully in patients with I-LRTI.

\section{Background}

Seasonal influenza epidemic accounted for an estimated 145000 (95\% uncertainty interval [UI] 99 000200000 ) deaths among all ages worldwide annually.[1] Although influenza vaccine is an available countermeasure to mitigate the considerable influenza-related mortality burden,[2] vaccine effectiveness is low compared with other viral vaccines, and the induced immune response is narrow and short-lived.[3] Current influenza vaccines are imperfect and the expected benefits of vaccination programs might be overstated, especially in elderly people.[4,5] For people who are not effectively prevented and are infected with influenza, neuraminidase inhibitors (NAIs) are recommended as the most effective antiviral agents.[6] However, in clinical practice, anti-influenza treatment for hospitalized patients with suspected influenza is not always initiated at admission and may be delayed while patients await results of diagnostic tests.[7] Even more, not all observed studies have confirmed the benefits of NAls treatment in hospitalized influenza patients.[8] Therefore, vaccines or antiviral agents alone tend not to reduce the burden of deaths caused by 
influenza, comprehensive evaluation based on clinical indicators and individual immune status remains critical.

Severe influenza originated from a respiratory infection but involved multiple organ systems, so it should also be caused by highly interacting networks of parameters in body instead of the isolated ones.[9-12] Particularly notable is the importance of omics analysis and the interrelationship between these multiple indicators, which can reflect both physical and non-physical associations between them.[13] There is no widely accepted clinical system for evaluating the prognosis of influenza patients. Although commonly used clinical evaluation systems, such as pneumonia severity index (PSI)[14] and Sepsis-related Organ Failure Assessment (SOFA) score[15] were multi-index evaluation systems, they were based on clinical data of patients with community-acquired pneumonia or sepsis, and lacked an assessment of the immune system and co-regulation network analysis. Therefore, the efficacy of these systems are limited in evaluating the prognosis of influenza patients. There have been no new reports of physicians exploring evaluation systems in recent years to assess the prognosis of patients with severe influenza.

Protein microarray has the advantages of high sensitivity and accuracy, which makes it possible to detect low abundant proteins in clinic.[16] In this work, we developed and applied a high-throughput and ultramicro plasma microarray platform to measure the expression of nine immunoglobulin isotypes (IgG, IgG14, $\lg A$, $\lg A 1-2, \lg M$ ) in hundreds of clinical plasma samples, which proved to be of high reproducibility and stability. The purpose of this study was to perform comprehensive analysis of the changes of immunological proteome and clinical variables, to explore novel pathological mechanisms through the immunoglobulin proteome-clinical variable co-regulation networks and to establish a prediction model for evaluating the prognosis of influenza patients.

\section{Methods}

Study Design and Participants

We conducted a prospective observational study, and collected patients with suspected influenzaassociated lower respiratory tract infection (I-LRTI) in emergency departments (EDs) of four hospitals (Beijing Chao-Yang Hospital, Capital Medical University; Beijing Di-Tan Hospital, Capital Medical University; Mi-Yun Teaching Hospital, Capital Medical University and Beijing Huai-Rou Hospital, Capital Medical University) during the winter of 2018-2019 in Beijing, China. All consecutive patients admitted to the EDs (including 24-hour fever clinics) for observation or hospitalization with suspected I-LRTIs were experienced rapid antigen detection and/or reverse transcription polymerase chain reaction (RT-PCR) test for influenza A and pulmonary imaging examination for LRTI. Those patients with insufficient evidence of influenza or LRTI and those who received hormone therapy within the last three months were excluded. All selected patients followed clinical guidelines for standardized management.[17, 18] Medical records were independently reviewed by two physicians. The endpoint was 28 -day mortality.

Definitions 
LRTI was defined as a group of acute clinical diseases, including community-acquired pneumonia (CAP), acute exacerbation of chronic obstructive pulmonary disease (COPD), or acute bronchitis.[19] I-LRTI was defined in LRTI patients with confirmed influenza infection. The definition of bacterial co-infection refers to our previous research.[20] Virus co-infection was defined in patients with one or more isolates by RT-PCR test obtained from a sputum, tracheal or bronchoscopic sample.

\section{Clinical Data Collection}

At admission, data regarding medical identification, demographic characteristics, medical history, comorbidities, clinical symptoms, physical examinations, laboratory results and radiological findings were collected. During hospitalization stay, microbiologic investigations, therapeutic management, invasive mechanical ventilation and vasopressor requirements were also recorded. The bloodwork results and microbial findings were provided by the Clinical Laboratory Department and Microbiology Laboratory Department of each hospital, respectively.

\section{Plasma Sample Preparation}

At the same time, $2 \mathrm{~mL}$ of peripheral blood was collected in an EDTA anticoagulant tube and thoroughly mixed. At $4{ }^{\circ} \mathrm{C}$, blood samples were centrifuged at $1300 \times \mathrm{g}$ for 10 minutes. After centrifugation, supernatant (plasma) was taken and loaded into a $1.5 \mathrm{~mL}$ centrifuge tube. Mark the sample number, date on the centrifugal tube and record the sample information. After processing the sample to save to $-80{ }^{\circ} \mathrm{C}$ refrigerator, avoid freeze and thaw.

\section{Plasma Microarrays}

Properly diluted plasma samples (from 10 to 500 -fold) and serially diluted standard immunoglobulins and then printed onto a 3D modified slide surface (Capital Biochip Corp, Beijing, China) in two replicates using an Arrayjet microarrayer (Roslin, UK). Phosphate-buffered saline (PBS) and bovine serum albumin (BSA, 1 $\mathrm{mg} / \mathrm{mL}$ ) (Sigma-Aldrich, MO, USA) were used as negative controls. After printing, the plasma microarrays were stored at $-20^{\circ} \mathrm{C}$ until use.

After equilibration to room temperature, the plasma microarrays were assembled into a microarray incubation tray and blocked with $500 \mu \mathrm{L} 1 \% \mathrm{BSA}$ in each well for 1 hour at room temperature. After removing the BSA, the arrays were incubated with the corresponding fluorescently-labeled antibody combinations for 1 hour at room temperature. The resulting slides were washed three times with PBS containing $0.05 \%$ (w/v) Tween 20 (PBST), $5 \mathrm{~min} /$ each, and $\mathrm{H}_{2} \mathrm{O}$ twice, $5 \mathrm{~min} /$ each. The slide was scanned using a Genepix 4000A microarray scanner (Molecular Devices, CA, USA). The fluorescent images were analyzed and the signal intensity was extracted using a GenePix Pro image analysis software (Molecular Devices, CA, USA). For each Ig subclass, the 4-paramter logistic standard curve between the absolute concentration and the signal intensity was fitted with properly diluted plasma samples by least-squares method and thus the absolute concentration of Ig subclass in plasma samples was imputed by Newton-GC method according to the fitted standard curve. 
Mann Whiney $U$ test was used to compare the difference of the means of two groups as the univariate values do not conform to the normal distribution. The exact Fisher's test was used to perform the independence statistical test. If $p$-value is under 0.05 , then the result is considered statistically significant. The Spearman correlation coefficient was calculated and the hierarchical correlation clustering heatmap was plotted with the $\mathrm{R}$ package corrplot. Logistic regression-based model was adopted for the discrimination of the survival/non-survival groups of the influenza patients with the recursive feature selection in the LOO cross-validation procedure. ROC curve was plotted and AUC was used to assess the discriminative efficacy of the trained classifier model. The statistical analyses were performed with $\mathrm{R}$. The logistic regression-based prediction and evaluation was performed with the Python packages SciKit-Learn and SciPy.

\section{Results}

\section{Patient Characteristics}

In the winter of 2018-2019, 280 patients with suspected influenza and accompanied LRTI from the four hospitals were screened. Of these patients, 173 were excluded: 166 had no laboratory positive test evidence for influenza, and 7 had recently been treated with hormones or immunosuppressants for autoimmune disease or solid organ transplantation. The final enrolled cohort consisted of 107 patients with I-LRTI, 85 from Beijing Chao-Yang Hospital, 9 from Beijing Di-Tan Hospital, 11 from Mi-Yun Teaching Hospital, and 2 from Beijing Huai-Rou Hospital. All the 107 patients were diagnosed with influenza A, 71 (66.4\%) of them with the H1N1 subtype. None of them were documented as having received an influenza vaccine. According to the 28-day mortality, the study cohort was divided into survival (80/107) and nonsurvival (27/107) groups. Flow chart was showed in Fig. 1.

Differential Regulation of Immunoglobulin Proteome and Clinical Indicators between Survival/Non-survival Groups

Each patient in the study cohort was investigated for demographic characteristics (age, sex, and body mass index (BMI)), days from onset to ED, co-morbidities (active cancer, chronic respiratory disease, coronary artery disease, chronic heart failure, chronic hepatopathy, chronic kidney disease, diabetes mellitus), vital signs (heart rate (HR), respiratory rate (RR), mean arterial pressure (MAP), and Glasgow Coma Scale (GCS)), clinical laboratory tests (blood routine examination, blood biochemistry, D-dimer, arterial blood gas analysis, Glycosylated hemoglobin (HbA1C), C-Reactive Protein (CRP), procalcitonin (PCT), and T-cell subset counts), microbiological detections, antiviral administrations, organ supports, and immunoglobulin quantification ( $\operatorname{lgG}, \lg$ G1-4, $\lg A, \lg A 1-2, \lg M)$. All of the above indicators were compared between the two groups (Table 1), and the indicators with significant or marginal differences (lymphocyte count (LY), monocytes count (MO), $\mathrm{CD} 3^{+} \mathrm{CD} 4^{+} \mathrm{T}$-cell count, $\mathrm{CD} 3^{+} \mathrm{CD} 8^{+} \mathrm{T}$-cell count, IgA, IgA1, IgG2, IgG4, $\mathrm{CRP}$, PCT, D-dimer, oxygenation index (OI), HbA1C, lactic acid (LAC), base excess of blood (BEB), lactic dehydrogenase ( $\mathrm{LDH})$, and a-hydroxybutyrate dehydrogenase $(\mathrm{HBDH})$ ) were also described in Fig. 2. The 
KS test indicated that $\mathrm{LY}, \mathrm{BEB}, \mathrm{D}$-dimer, $\mathrm{HbA1C}$, LDH, HBDH, CRP, PCT and IgG2 between survival and nonsurvival groups are statistically differentially distributed, and meanwhile MO, LAC and IgA are of marginally statistically differentially distributed. To measure effects of age, sex and days from onset on the concentration of Ig subclasses, generalized multivariate linear analysis was performed, in which the concentration of Ig subclass is taken as the dependent variable and age, sex, days from onset and the survival/non-survival group together as the independent variables. The results suggested that $\lg \mathrm{G} 2$ concentration is statistically impacted with age, and IgA concentration with both age and days from onset. 
Table 1

Comparison of clinical features and immunoglobulin proteome quantification between the survivors and non-survivors in patients with I-LRTI

\begin{tabular}{|c|c|c|c|c|}
\hline Variables & $\begin{array}{l}\text { Total } \\
n=107\end{array}$ & $\begin{array}{l}\text { Survivors } \\
n=80\end{array}$ & $\begin{array}{l}\text { Non-survivors } \\
n=27\end{array}$ & $\begin{array}{l}\mathrm{p} \\
\text { value }\end{array}$ \\
\hline $\begin{array}{l}\text { Age, years, } \\
\text { median }\left(\mathrm{IQR}^{\mathrm{a}}\right)\end{array}$ & $64(50,79)$ & $63(49,78)$ & $67(56,81)$ & 0.254 \\
\hline \multicolumn{5}{|l|}{ Age group, $\mathrm{n}(\%)$} \\
\hline age $<45$ & $15(14.0)$ & $13(16.3)$ & $2(7.4)$ & 0.410 \\
\hline $45 \leq$ age $<65$ & $42(39.3)$ & $32(40.0)$ & $10(37.0)$ & 0.785 \\
\hline age $\geq 65$ & $50(46.7)$ & $35(43.8)$ & $15(55.6)$ & 0.288 \\
\hline Sex (male), n(\%) & $67(62.6)$ & $51(63.8)$ & 16(59.3) & 0.677 \\
\hline $\begin{array}{l}\mathrm{BMI}\left(\mathrm{kg} / \mathrm{m}^{2}\right) \\
\text { median(IQR) }\end{array}$ & $23.7(21.6,26.6)$ & $23.7(21.5,26.6)$ & $24.2(22.0,26.6)$ & 0.769 \\
\hline \multicolumn{5}{|l|}{$\begin{array}{l}\text { Co-morbidities, } \\
\mathrm{n}(\%)\end{array}$} \\
\hline Active cancer & $3(2.8)$ & $3(3.8)$ & $0(0)$ & 0.570 \\
\hline $\begin{array}{l}\text { Chronic } \\
\text { respiratory } \\
\text { disease }^{b}\end{array}$ & $13(12.1)$ & $11(13.8)$ & $2(7.4)$ & 0.595 \\
\hline $\begin{array}{l}\text { Coronary artery } \\
\text { disease }\end{array}$ & $25(23.4)$ & 19(23.8) & $6(22.2)$ & 0.871 \\
\hline $\begin{array}{l}\text { Chronic heart } \\
\text { failure }\end{array}$ & $5(4.7)$ & $4(5.0)$ & $1(3.7)$ & 0.999 \\
\hline $\begin{array}{l}\text { Chronic } \\
\text { hepatopathy }\end{array}$ & $3(2.8)$ & $2(2.5)$ & $1(3.7)$ & 0.999 \\
\hline $\begin{array}{l}\text { Chronic kidney } \\
\text { disease }\end{array}$ & $10(9.3)$ & $7(8.8)$ & $3(11.1)$ & 0.999 \\
\hline $\begin{array}{l}\text { Diabetes } \\
\text { mellitus }\end{array}$ & $27(25.2)$ & $20(25.0)$ & $7(25.9)$ & 0.924 \\
\hline
\end{tabular}

a IQR: inter-quartile range;

${ }^{b}$ Chronic respiratory disease: asthma, chronic obstructive pulmonary disease, pulmonary fibrosis, bronchiectasis;

${ }^{c}$ NAls: Neuraminidase inhibitors. 


\begin{tabular}{|c|c|c|c|c|}
\hline Variables & $\begin{array}{l}\text { Total } \\
n=107\end{array}$ & $\begin{array}{l}\text { Survivors } \\
n=80\end{array}$ & $\begin{array}{l}\text { Non-survivors } \\
n=27\end{array}$ & $\begin{array}{l}\mathrm{P} \\
\text { value }\end{array}$ \\
\hline $\begin{array}{l}\text { Days from } \\
\text { onset to ED, } \\
\text { median(IQR) }\end{array}$ & $4(2,7)$ & $3.5(2,7)$ & $5(3,7)$ & 0.124 \\
\hline $\begin{array}{l}\text { NAls }{ }^{c} \\
\text { administration, } \\
\mathrm{n}(\%)\end{array}$ & $90(84.1)$ & 70(87.5) & $20(74.1)$ & 0.178 \\
\hline $\begin{array}{l}\text { NAls } \\
\text { administration } \\
\text { within } 48 \text { hours, } \\
\text { n(\%) }\end{array}$ & 10(9.3) & $9(11.3)$ & 1(3.7) & 0.434 \\
\hline $\begin{array}{l}\text { Bacterial co- } \\
\text { infection, } \mathrm{n}(\%)\end{array}$ & 17(15.9) & 11(13.8) & $6(22.2)$ & 0.461 \\
\hline $\begin{array}{l}\text { S. aureus co- } \\
\text { infection, n(\%) }\end{array}$ & $7(6.5)$ & $3(3.8)$ & $4(14.8)$ & 0.066 \\
\hline $\begin{array}{l}\text { Virus co- } \\
\text { infection, } n(\%)\end{array}$ & $23(21.5)$ & $16(20.0)$ & $7(25.9)$ & 0.517 \\
\hline $\begin{array}{l}\text { Mechanical } \\
\text { ventilation, } \mathrm{n}(\%)\end{array}$ & $27(25.2)$ & $9(11.3)$ & 18(66.7) & $<0.001$ \\
\hline $\begin{array}{l}\text { Vasoactive } \\
\text { agents, n(\%) }\end{array}$ & 18(16.8) & $8(10.0)$ & $10(37.0)$ & 0.003 \\
\hline $\begin{array}{l}\text { Heart rate, } \\
\text { beats/min, } \\
\text { median(IQR) }\end{array}$ & $97(81,112)$ & $97(81,112)$ & $104(81,118)$ & 0.403 \\
\hline $\begin{array}{l}\text { Respiratory rate, } \\
\text { breaths/min, } \\
\text { median(IQR) }\end{array}$ & $22(20,27)$ & $21(20,26)$ & $22(20,29)$ & 0.690 \\
\hline $\begin{array}{l}\text { Mean arterial } \\
\text { pressure, } \\
\text { mmHg, } \\
\text { median(IQR) }\end{array}$ & $95(85,109)$ & $95(85,107)$ & $96(82,110)$ & 0.971 \\
\hline $\begin{array}{l}\text { Glasgow Coma } \\
\text { Scale, } \\
\text { median(IQR) }\end{array}$ & $15(15,15)$ & $15(15,15)$ & $15(15,15)$ & 0.574 \\
\hline
\end{tabular}

a IQR: inter-quartile range;

${ }^{b}$ Chronic respiratory disease: asthma, chronic obstructive pulmonary disease, pulmonary fibrosis, bronchiectasis;

${ }^{\mathrm{c}}$ NAls: Neuraminidase inhibitors. 


\begin{tabular}{|c|c|c|c|c|}
\hline Variables & $\begin{array}{l}\text { Total } \\
n=107\end{array}$ & $\begin{array}{l}\text { Survivors } \\
\mathrm{n}=80\end{array}$ & $\begin{array}{l}\text { Non-survivors } \\
\mathrm{n}=27\end{array}$ & $\begin{array}{l}\mathrm{P} \\
\text { value }\end{array}$ \\
\hline \multicolumn{5}{|l|}{$\begin{array}{l}\text { Clinical } \\
\text { parameters, } \\
\text { median(IQR) }\end{array}$} \\
\hline $\begin{array}{l}\text { White blood cell, } \\
\text { WBC, }\left(\times 10^{9} / \mathrm{L}\right)\end{array}$ & 7.72(4.79,10.79) & 7.94(5.01,10.55) & $6.86(4.43,11.33)$ & 0.846 \\
\hline $\begin{array}{l}\text { Neutrophil, NE, } \\
\left(\times 10^{9} / \mathrm{L}\right)\end{array}$ & $6.19(3.77,8.81)$ & $6.20(3.75,8.75)$ & $6.07(3.85,10.30)$ & 0.578 \\
\hline $\begin{array}{l}\text { Lymphocyte, LY, } \\
\left(\times 10^{9} / \mathrm{L}\right)\end{array}$ & $0.71(0.44,1.24)$ & $0.86(0.50,1.37)$ & $0.50(0.38,0.79)$ & 0.012 \\
\hline $\begin{array}{l}\text { Monocyte, MO, } \\
\left(\times 10^{9} / \mathrm{L}\right)\end{array}$ & $0.36(0.16,0.62)$ & $0.40(0.19,0.62)$ & $0.26(0.09,0.61)$ & 0.050 \\
\hline NK cell, $(/ \mu \mathrm{L})$ & $9.60(5.73,13.15)$ & $9.55(7.20,16.43)$ & $9.75(5.43,13.15)$ & 0.652 \\
\hline $\begin{array}{l}\mathrm{CD}^{+} \mathrm{CD}^{+} \mathrm{T} \text { cell, } \\
(/ \mu \mathrm{L})\end{array}$ & $199.50(114.25,355.00)$ & $201.50(130.75,386.50)$ & $169.00(87.50,238.00)$ & 0.077 \\
\hline $\begin{array}{l}\mathrm{CD}^{+} \mathrm{CD}^{+} \mathrm{T} \text { cell, } \\
(/ \mu \mathrm{L})\end{array}$ & $117.50(70.25,208.00)$ & $123.50(78.50,278.75)$ & $107.00(45.75,174.50)$ & 0.080 \\
\hline $\begin{array}{l}\text { D-dimer, }(\mathrm{mg} / \mathrm{L} \\
\text { FEU) }\end{array}$ & $1.48(0.89,3.54)$ & $1.21(0.72,2.18)$ & $2.43(1.85,13.34)$ & $<.001$ \\
\hline $\begin{array}{l}\text { Lactate } \\
\text { dehydrogenase, } \\
\text { LDH, (U/L) }\end{array}$ & $355.0(223.0,576.7)$ & $302.0(216.5,511.1)$ & $482.0(302.0,642.0)$ & 0.019 \\
\hline $\begin{array}{l}\text { a- } \\
\text { hydroxybutyrate } \\
\text { dehydrogenase, } \\
\mathrm{HBDH},(\mathrm{U} / \mathrm{L})\end{array}$ & 275.5(182.0,423.3) & $236.0(181.0,367.3)$ & $375.5(259.5,473.0)$ & 0.008 \\
\hline $\begin{array}{l}\text { Glycosylated } \\
\text { hemoglobin, } \\
\text { HbA1C, }(\%)\end{array}$ & $6.1(5.8,6.9)$ & $6.1(5.7,6.7)$ & $6.6(6.1,7.7)$ & 0.015 \\
\hline $\begin{array}{l}\text { Lactic acid, LAC, } \\
(\mathrm{mmol} / \mathrm{L})\end{array}$ & $1.2(1.0,1.7)$ & $1.1(0.9,1.7)$ & $1.5(1.2,1.9)$ & 0.023 \\
\hline $\begin{array}{l}\text { Oxygenation } \\
\text { index, Ol }\end{array}$ & $263(151,381)$ & $268(162,393)$ & $194(116,294)$ & 0.059 \\
\hline \multicolumn{5}{|c|}{ a IQR: inter-quartile range; } \\
\hline \multicolumn{5}{|c|}{$\begin{array}{l}{ }^{b} \text { Chronic respiratory disease: asthma, chronic obstructive pulmonary disease, pulmonary fibrosis, } \\
\text { bronchiectasis; }\end{array}$} \\
\hline
\end{tabular}




\begin{tabular}{|c|c|c|c|c|}
\hline Variables & $\begin{array}{l}\text { Total } \\
n=107\end{array}$ & $\begin{array}{l}\text { Survivors } \\
n=80\end{array}$ & $\begin{array}{l}\text { Non-survivors } \\
n=27\end{array}$ & $\begin{array}{l}p \\
\text { value }\end{array}$ \\
\hline $\begin{array}{l}\mathrm{HCO}_{3}^{-}, \\
\left(\mathrm{mmol}^{-} \mathrm{L}\right)\end{array}$ & 21.1(18.6,23.9) & $22.5(20.0,24.9)$ & $20.0(17.1,22.5)$ & 0.023 \\
\hline $\begin{array}{l}\text { Base Excess of } \\
\text { Blood, BEB, } \\
(\mathrm{mmol} / \mathrm{L})\end{array}$ & $-1.0(-3.8,0.9)$ & $-0.6(-3.3,1.2)$ & $-3.7(-5.0,-0.4)$ & 0.010 \\
\hline $\begin{array}{l}\text { C-Reactive } \\
\text { Protein, CRP, } \\
\text { (mg/dL) }\end{array}$ & $12.1(4.2,22.1)$ & $9.6(3.0,22.8)$ & $19.6(14.2,25.8)$ & 0.018 \\
\hline $\begin{array}{l}\text { Procalcitonin, } \\
\text { PCT, (ng/mL) }\end{array}$ & $0.22(0.08,1.01)$ & $0.16(0.06,0.60)$ & $0.91(0.23,6.43)$ & 0.001 \\
\hline \multicolumn{5}{|l|}{$\begin{array}{l}\text { Plasma } \\
\text { immunoglobulin } \\
\text { quantification, } \\
(\mu \mathrm{g} / \mathrm{mL}), \text { mean } \\
\pm \text { SD }\end{array}$} \\
\hline $\lg A$ & $\begin{array}{l}4277.955517 \pm \\
1751.127383\end{array}$ & $\begin{array}{l}4495.494011 \pm \\
1799.218731\end{array}$ & $\begin{array}{l}3633.397017 \pm \\
1445.182929\end{array}$ & 0.053 \\
\hline $\lg A 1$ & $\begin{array}{l}3251.871483 \pm \\
1575.089408\end{array}$ & $\begin{array}{l}3411.345318 \pm \\
1646.654368\end{array}$ & $\begin{array}{l}2779.356417 \pm \\
1251.261989\end{array}$ & 0.087 \\
\hline $\lg A 2$ & $\begin{array}{l}326.738305 \pm \\
148.035244\end{array}$ & $\begin{array}{l}330.15051070 \pm \\
139.051213\end{array}$ & $\begin{array}{l}316.628064 \pm \\
174.505309\end{array}$ & 0.347 \\
\hline $\lg G$ & $\begin{array}{l}22497.252537 \pm \\
10921.188428\end{array}$ & $\begin{array}{l}22082.874174 \pm \\
10369.593861\end{array}$ & $\begin{array}{l}23725.040279 \pm \\
12547.880435\end{array}$ & 0.596 \\
\hline $\lg \mathrm{G} 1$ & $\begin{array}{l}6682.518079 \pm \\
3470.015276\end{array}$ & $\begin{array}{l}6569.600710 \pm \\
2892.282678\end{array}$ & $\begin{array}{l}7017.088061 \pm \\
4849.447558\end{array}$ & 0.628 \\
\hline $\lg G 2$ & $\begin{array}{l}167.928721 \pm \\
121.118981\end{array}$ & $\begin{array}{l}189.688541 \pm \\
129.383245\end{array}$ & $\begin{array}{l}103.455179 \pm \\
56.304086\end{array}$ & $\begin{array}{l}<.001 \\
0.001\end{array}$ \\
\hline $\lg G 3$ & $\begin{array}{l}24.179282 \pm \\
33.797908\end{array}$ & $\begin{array}{l}25.921704 \pm \\
36.743783\end{array}$ & $\begin{array}{l}19.016550 \pm \\
22.755197\end{array}$ & 0.168 \\
\hline $\operatorname{lgG} 4$ & $\begin{array}{l}21.765171 \pm \\
25.443257\end{array}$ & $\begin{array}{l}21.888248 \pm \\
20.932293\end{array}$ & $\begin{array}{l}21.400501 \pm \\
36.162335\end{array}$ & 0.056 \\
\hline $\lg M$ & $\begin{array}{l}3515.750491 \pm \\
2696.014576\end{array}$ & $\begin{array}{l}3578.764165 \pm \\
3087.582291\end{array}$ & $\begin{array}{l}3329.043310 \pm \\
786.461713\end{array}$ & 0.683 \\
\hline \multicolumn{5}{|c|}{ a IQR: inter-quartile range; } \\
\hline \multicolumn{5}{|c|}{$\begin{array}{l}\text { b Chronic respiratory disease: asthma, chronic obstructive pulmonary disease, pulmonary fibrosis, } \\
\text { bronchiectasis; }\end{array}$} \\
\hline
\end{tabular}


Co-regulatory Network Analysis of Clinical Indicators and Immunoglobulin Proteome Quantification in the Survival/Non-survival Groups

Co-regulatory network was used to analyze and compare the correlation characteristics across clinical indicators and immunoglobulin quantification for the survivors and the non-survivors respectively, and was showed by hierarchical correlation clustering heatmap (Fig. 3). Red color represents a positive correlation, blue color represents a negative correlation, and the darker the color, the stronger the correlation. In the heatmap of the survival group, different variables were respectively separated into two red-colored positively correlated clusters (Fig. 3A). Cluster 1 included IgA, IgA1-2, IgG, IgG1-4, WBC, NE, MO, NK cell, and age, and these variables were related to immunity. Cluster 2 included CRP, PCT, D-dimer, LDH, LBDH, HR and $\mathrm{RR}$, and these variables revealed the severity of infection. In the heatmap of the non-survival group, the indicator clusters were re-clustered (Fig. 3B). Cluster 1 included days from onset to ED, IgM, sex, and GCS. Cluster 2 contained indicators of the severity of the infection (LAC, LDH, HBDH, MAP, HR, RR, D-dimer, CRP and PCT). Cluster 3 included partial immunoglobulin family molecules (IgA, IgA1, IgG, IgG1, IgG2, IgG4) and BMI. Cluster 4 included both cell-immune-related indicators (age, WBC, NE, MO, LY, CD3 ${ }^{+} \mathrm{CD} 4^{+} \mathrm{T}$-cell, and $\mathrm{CD}^{+} \mathrm{CD} 8^{+} \mathrm{T}$-cell), $\mathrm{Ol}, \mathrm{HbA} 1 \mathrm{C}$ and bacterial co-infection. Cluster 5 included NK cell, IgG3, IgA2, BEB and virus co-infection.

Predictive Model of Clinical Outcomes

We investigated the potential of these variables in the prediction of survivors/non-survivors, and calculated the AUCs of these differentially regulated variables. Based on the statistical difference, we performed iterative recursive feature selection and found the optimal combination of features. Logistic regressionbased classifier was trained to discriminate survivors and non-survivors. To evaluate the predictive efficacy of the trained model objectively, LOO cross validation was employed to ensure the mutual independence between the training dataset and the testing dataset. In LOO cross validation, the training and validation steps were repeated $\mathrm{N}$ times, and for each step one sample was selected for validation and the rest were used for model training iteratively ( $\mathrm{N}$ denoted with the sample number). Then random sampling (sampling ratio $95 \%$, iteration times 1000 ) was performed to calculate the $95 \%$ confidence intervals (Cls) of the AUC of the prediction model. The AUCs of IgG2, IgA and the combination the two were $0.725(95 \% \mathrm{Cl} 0.702-$ 0.748), 0.575 (95\% Cl 0.404-0.694) and 0.737 (95\% Cl 0.714-0.760), respectively (Fig. 4A). The combined prediction model with nine variables (D-dimer, days from onset to ED, IgA, IgG2, LAC, LY, MO, Staphylococcus aureus (S.aureus) co-infection and age) reached the maximum AUC value of 0.810 (95\% Cl 0.755-0.839) (Fig. 4B). The AUCs of D-dimer, LAC, LY, and MO were 0.722 (95\% Cl 0.690-0.751), 0.662 (95\% Cl 0.634-0.684), 0.644 (95\% Cl 0.607-0.673), and 0.572 (95\% Cl 0.536-0.609), respectively. All the pairwise comparisons across each of the single-factor models with the combination prediction model were of statistical significance.

To further evaluate the selected optimal indicators for the prediction model, the unsupervised participantfeature hierarchical correlation clustering was also performed and the participants were separated into two clusters. The majority of the actual non-survivors were discriminated into the same cluster, which indicated 
the consistency between the clustered results and the actual grouping (Fig. 4C). This proved the feature combination's discriminative efficacy of the survivors/non-survivors.

Validation of the Model by Disease Severity Evaluation

The risk of progression to critical conditions, including mechanical ventilation requirements or vasoactive agent requirements, can also be evaluated using the predictive model and for mechanical ventilation or vasoactive agent apparently there exists statistical difference between survivors and non-survivors in practice. For the requirement of mechanical ventilation, 15 (15/37) predicted non-survivors and 12 (12/70) predicted survivors should receive mechanical ventilation respectively, exhibiting the statistical difference between two predicted groups (Fig. 5A), which is in consistency with the actual facts (In the study cohort, $18(18 / 27)$ non-survivors and $9(9 / 80)$ survivors actually received mechanical ventilation (Fig. 5B)). For the requirement of vasoactive agent, $10(10 / 37)$ predictive non-survivors and $8(8 / 70)$ predicted survivors should receive vasoactive agents respectively, exhibiting the marginally statistical difference between two predicted groups (Fig. 5C), which is in accordance with the actual facts (In the study cohort, 10 (10/27) non-survivors and $8(8 / 80)$ survivors received vasoactive agents, respectively (Fig. 5D)). The results of both mechanical ventilation and vasoactive agents demands proved the potential of the predictive model.

\section{Discussion}

This study evaluated the prognosis of patients with I-LRTI by investigating clinical indicators and immunoglobulin quantification, all of which were taken from the initial assessment of the patient's ED visit. For the reason that corticosteroids and immunosuppressants have multiple anti-inflammatory and immunosuppressive effects and influence virtually all immune cells,[21] patients who had recently received immunosuppressive or hormone therapy were excluded, but patients with other underlying diseases were also included. Chronic pulmonary, cardiovascular, renal, hepatic, hematologic, metabolic, or neurologic disorders put influenza patients at high risk of complications, but our study did not identify these underlying conditions as risk factors for mortality. Current findings were consistent with the results of a multicenter study in Spain involving 2,901 patients, showing that underlying diseases and physiological status were not independent risk factors for mortality in severe influenza patients.[22]

Although there was a high proportion of NAls administration at the time of admission, only a few patients were administrated within 48 hours from the onset of influenza-like symptoms. Both the proportion of patients who had started NAls at the time of admission and the proportion of patients who had started NAls within 48 hours from onset were lower in the non-survivors than that in the survivors, in spite of no statistical differences. Our results still supported previous observational studies that antiviral treatment of critically ill adult influenza patient with a NAI was associated with survival benefit.[23, 24] However, problems such as delayed administration of NAls ( $>48$ hours), drug resistance and induced cytokine storms still put severe cases at risk of early mortality $[25,26]$. Another study argued that outpatient data on patients with relatively mild illnesses should not form the basis for policies on the management of more severe disease.[27] Therefore, comprehensive clinical evaluation and multi-system support are still crucial and indispensable. 
Clinicians tend to evaluate the prognosis of I-LRTI patients with multiple factors rather than single factor, but there is currently no efficacious evaluation system, which could reflect disturbances in the physiological system. Host immunity, especially humoral immunity, plays an important role in the defense and elimination of influenza viruses. Influenza virus infection, as an initiating factor, can lead to multiple organ dysfunction and usually co-infect with pathogenic bacteria. This process is associated with higher mortality rate than individual viral infection.[28] The complex interaction of initial influenza virus, copathogen invasion and host immune response complicates the pathophysiological process, and its molecular biological mechanism needs to be explored urgently.[29] In order to facilitate clinical application, we explored the changing pattern of simple and easily available biomarkers to reveal the underlying pathophysiological signals in I-LRTI status and their changes prior to death. In this study, co-regulation networks and a multi-factor model were established by combining immune cell count, immunoglobulin quantification and clinical indicators routinely measured in clinic.

We developed a large-scale, ultra-micro plasma immunoglobulin quantification chip, which has high reproducibility (Pearson's $r>0.9$ ) and high sensitivity ( attomolar). Through the platforms, we screened the immunoglobulin concentration of hundreds of plasma samples within 20 minutes with low cost. Our results showed that decreased IgA, IgA1, and IgG2 were associated with mortality. Two studies demonstrated respectively that impairment of the antibody response to specific microbial antigens predisposed patients with IgG2, IgG3 and IgA deficiencies to recurrent infections.[30, 31] Shield JP et al. investigated the immunology of eight patients with recurrent bacterial infections in infancy or early childhood and attributed this phenomenon to their lower IgG2 levels and poor production of specific antibodies against common pathogens.[32] In these studies, all enrolled patients had normal serum total IgG range, but had selective IgG-subclass deficiency. IgG2 is a weak mediator of FcyR and complement mediated effector functions, and is involved in the response to polysaccharide antigens.[33] Influenza virus elicits a vigorous non-virus-specific lgG2a response, which is dependent on cognate T-B interactions. A robust virus-specific IgA response with virus-neutralizing activity is crucial for eliminating influenza virus. [34] Low concentrations of IgG2 often occur in association with a deficiency in IgG4 and/or IgA1 and IgA2. [35] Thus, inadequate $\lg G 2$ and $\lg A$ response may be the underlying cause of infection progression and poor prognosis.

The detection of immunoglobulin subclass has not been routinely carried out in clinical practice, but our results showed that many laboratory indicators provided strong evidence for prognosis in patients with ILRTI. First, elderly patients still have the highest mortality rate.[36] In the age stratification of our cohort, mortality rate increased with age, which may be related to body's organ systems aging, especially immune system aging. Hernandez-vargas EA et al. confirmed in mouse experiments that immune activation capacity was weakened in elderly mice after influenza virus infection, and thus the efficiency of clearing influenza virus was decreased than it was in younger mice.[37] Second, a decrease in immune cell count predicts a poor prognosis. Lymphocytopenia was considered as a risk factor for mortality in patients with pneumonia caused by influenza virus.[38] Decreased monocytes was found to have a marginal difference between the survivors and the non-survivors, which may also be a prognostic factor. So far, few studies have been reported, and further large sample validation is required. The decrease of $C D 3^{+} C D 4^{+} T$-cell and 
$\mathrm{CD}^{+} \mathrm{CD} 8^{+} \mathrm{T}$-cell had been proved to be closely associated with increased mortality and deteriorated primary and subsequent infections in influenza A virus infected animals.[39, 40] Similar results were found in our cohort study, where decreased $\mathrm{CD} 3^{+} \mathrm{CD} 4^{+} \mathrm{T}$-cell and $\mathrm{CD} 3^{+} \mathrm{CD} 8^{+} \mathrm{T}$-cell counts were associated with mortality and bacterial co-infection (especially S. aureus co-infection). Third, some biomarkers such as Ddimer, $\mathrm{LDH}, \mathrm{HBDH}, \mathrm{HbA} 1 \mathrm{C}, \mathrm{LAC}, \mathrm{HCO}_{3}{ }^{-}, \mathrm{BEB}, \mathrm{CRP}$ and PCT were also strong prognostic factors. A surge of LDH suggested metabolic reprogramming, and was associated with increased mortality in patients with sepsis.[41] Currently, we found a similar phenomenon in the influenza cohort. Our previous study confirmed that elevated PCT levels in influenza patients reflected bacterial co-infection, which was an independent risk factor for mortality.[42]

We further comprehensively analyzed the immunoglobulin profile and laboratory parameters in patients with I-LRTI between survivors and non-survivors and established corresponding co-regulatory network models for different groups. In the cluster heatmap, we found that in the survival group, indicators reflecting the body's immune status, including IgA, IgA1-2, IgG, IgG1-4, WBC, NE, MO, NK cell, and age, were nearly clustered together. In the same way, indicators reflecting the severity of infection, including CRP, PCT, D-dimer, LDH, and LBDH, were clustered together. There always be positive correlations between IgG1 and IgG, since IgG1 constitutes the main component (60\%-75\%) of IgG.[43] However, we found that correlation patterns between indicators were apparently modified in the non-survival group compared with the survival group. The association between bacterial co-infection and T cell counts was present in the non-survival group, suggesting a potential role of their interaction between impaired cellular immune and bacterial coinfection. A recent study similarly showed that the nosocomial co-infection of A. baumannii was associated with the dysregulation of immune responses including deranged T-cell counts.[44] In our previous studies, patients with influenza was found to be susceptible to community-acquired bacterial coinfections, and was characterized by a synergistic lethal effect of influenza and S. aureus.[20] In view of the low sensitivity and lagging results of bacteriological investigation, our another study have quantified bacterial co-infection in influenza patients using PCT and identified an independent association between PCT and 28-day mortality.[42] However, the correlation between bacterial co-infection in hospitalized patients with influenza and their immune indicators has not been revealed. In the current study, we further elucidated the correlation between this phenomenon and T cell mediated immunity. This finding is of great clinical significance. One is that $\mathrm{T}$ cell counts should be instantly detected to assess the risk stratification when a severe influenza patient visits ED. The other is to predict the risk of bacterial co-infection in patients with I-LRTI based on the T cell counts, and then to manage antibiotics and regulate immune function as early as possible.

In this study, we have created an assessment model to predict mortality due to I-LRTI by combining nine variables, including IgG2, D-dimer, LAC, LY, MO, IgA, days from onset, age, and S. aureus co-infection. The first to the eighth variables in the model were continuous, and they were ordered according to the contribution of each single variable to the model, which was quantified as area under ROC curve. To make the evaluation of the prediction model closer to the real world, LOO cross validation was adopted to implement the mutual independence between model training and validation. The prediction model was more powerful than the isolated use of each of the original variables based on an AUC comparison. 
The current study has several limitations that prevent broad generalization of the prediction model. First, the relatively small number of patients may limit external validity, and large sample validation is required. Second, IgG2 quantification cannot be implemented in clinical practice, and the predictive power of the model without IgG2 may be weakened in clinical application. It is suggested that the testing of Ig subclass should be carried out in hospitals in the future. Third, influenza vaccination rates in our country were low, and the information was usually poorly documented in medical history, preventing any conclusion on this point. Fourth, all the variables mentioned in this study were dynamic changes after the body was infected with influenza virus. This study only captured a single time point at the time of admission, which failed to fully reflect the progress of patients' illness.

\section{Conclusions}

The main conclusions and innovations of this study were as follows: I) Quantitative analysis of Ig and Igsubclass by proteomics constitutes part of immune evaluation, which is especially important for the prognosis assessment in patients with I-LRTI. Proteomics, with its superiorities of high throughput, high sensitivity, high accuracy and low cost, may become an important technique in medicine in the future. II) Cluster analysis revealed that the body's homeostasis in the non-survivors had been disrupted by the time the patients were admitted to the hospital. Moreover, an important finding was that lethal bacterial (especially Staphylococcus aureus) co-infection was closely associated with cellular immunity (WBC, NE, $\mathrm{MO}, \mathrm{LY}, \mathrm{CD} 3^{+} \mathrm{CD} 4^{+} \mathrm{T}$-cell, and $\mathrm{CD} 3^{+} \mathrm{CD} 8^{+} \mathrm{T}$-cell), $\mathrm{OI}, \mathrm{HbA} 1 \mathrm{C}$ and age. III). So far, no accurate and effective prediction model for prognosis in patients with I-LRTI has been reported. This study created a multidimensional and cross-verified prediction model for clinical application.

\section{Abbreviations List}

NAls, neuraminidase inhibitors; Ig, immunoglobulin; I-LRTI, influenza-associated lower respiratory tract infection; ED, emergency department; RT-PCR, reverse transcription polymerase chain reaction; ROC, receiver operating characteristics; $A U C$, area under receiver operating characteristics curve; $A(H 1 N 1)$, pandemic 2009 influenza $A(H 1 N 1) ; B M I$, body mass index; HR, heart rate; RR, respiratory rate; MAP, mean arterial pressure; GCS, Glasgow Coma Scale; HbA1C, Glycosylated hemoglobin; CRP, C-Reactive Protein; PCT, procalcitonin; WBC, white blood cell; NE, neutrophil; LY, lymphocyte; MO, monocytes; OI, oxygenation index; LAC, lactic acid; BEB, base excess of blood; $L D H$, lactic dehydrogenase; $H B D H$, a-hydroxybutyrate dehydrogenase; S.aureus, Staphylococcus aureus, $\mathrm{Cl}$, confidence interval; LOO, leave-one-out; KS test, Kolmogorov-Smirnov test

\section{Declarations}

\section{Ethics approval and consent to participate}

This study was approved by the Institutional Review Board and Medical Ethics Committee of Beijing ChaoYang Hospital (Ethical approval number: 2019-ke-301), which was also recognized by ethics committees at the three other hospitals. Verbal consent had been obtained for all forms of personally identifiable data 
including biomedical, clinical, and biometric data from study participants or their legal guardian. As this study is an observational study, no written consent was obtained. Verbal informed consent had been approved by the Ethics Committee in this study.

\section{Consent for publication}

Not applicable.

\section{Availability of data and materials}

The datasets used and analyzed during the current study are available from the corresponding author upon reasonable request.

\section{Competing interests}

The authors declare that they have no competing interests.

\section{Funding}

This work was supported by the Capital Clinical Characteristic Applied Research Project (Z171100001017057), 1351 Talent Cultivation Program (CYMY-2017-23), National Natural Science Foundation of China (81673040, 31870823), the National Program on Key Basic Research Project (2017YFC0906703, 2018ZX09733003), the State Key Laboratory of Proteomics (SKLP-0201703, SKLPK201505). The funding bodies had no influence on the design of the study and collection, analysis, and interpretation of data and in writing the manuscript

\section{Authors' contributions}

FT and DW had full access to all the data in the study and takes responsibility for the integrity of the data and the accuracy of the data analysis, including and especially any adverse effects. X-MZ, J-HL and J-YD contributed to immunoglobulin quantification, data collection and analysis. FT, DW, Y-DY, LG, Y-FC, S-FM, XTL, W-PY, X-JY and XM contributed to data collection and analysis and manuscript preparation and review. S-BG and X-BY conceived and designed the research, guided the experiment, analyzed and interpreted the data, helped to draft the manuscript and revised it critically for important intellectual content and was responsible for the overall content as guarantor. All authors gave final approval of the version to be published and agreed to be accountable for all aspects of the work in ensuring that questions related to the accuracy or integrity of any part of the work are appropriately investigated and resolved.

\section{Acknowledgements:}

The authors would like to thank the patients who participated in this study, and also thank the funders.

\section{References}


1. Troeger CE BB, Khalil IA, et al: Mortality, morbidity, and hospitalisations due to influenza lower respiratory tract infections, 2017: an analysis for the Global Burden of Disease Study 2017. The Lancet Respiratory medicine 2019, 7(1):69-89.

2. Iuliano AD, Roguski KM, Chang HH, Muscatello DJ, Palekar R, Tempia S, Cohen C, Gran JM, Schanzer D, Cowling BJ et al: Estimates of global seasonal influenza-associated respiratory mortality: a modelling study. Lancet (London, England) 2018, 391(10127):1285-1300.

3. Krammer F: The human antibody response to influenza A virus infection and vaccination. Nature reviews Immunology 2019, 19(6):383-397.

4. Pebody R, Warburton F, Ellis J, Andrews N, Potts A, Cottrell S, Reynolds A, Gunson R, Thompson C, Galiano $\mathrm{M}$ et al: End-of-season influenza vaccine effectiveness in adults and children, United Kingdom, 2016/17. Euro surveillance : bulletin Europeen sur les maladies transmissibles = European communicable disease bulletin 2017, 22(44).

5. Sullivan SG, Chilver MB, Carville KS, Deng YM, Grant KA, Higgins G, Komadina N, Leung VK, MinneySmith CA, Teng D et al: Low interim influenza vaccine effectiveness, Australia, 1 May to 24 September 2017. Euro surveillance : bulletin Europeen sur les maladies transmissibles = European communicable disease bulletin 2017, 22(43).

6. Doll MK, Winters N, Boikos C, Kraicer-Melamed H, Gore G, Quach C: Safety and effectiveness of neuraminidase inhibitors for influenza treatment, prophylaxis, and outbreak control: a systematic review of systematic reviews and/or meta-analyses. The Journal of antimicrobial chemotherapy 2017, 72(11):2990-3007.

7. Appiah GD, Chaves SS, Kirley PD, Miller L, Meek J, Anderson E, Oni O, Ryan P, Eckel S, Lynfield R et al: Increased Antiviral Treatment Among Hospitalized Children and Adults With Laboratory-Confirmed Influenza, 2010-2015. Clinical infectious diseases : an official publication of the Infectious Diseases Society of America 2017, 64(3):364-367.

8. Hurt AC, Kelly H: Debate Regarding Oseltamivir Use for Seasonal and Pandemic Influenza. Emerging infectious diseases 2016, 22(6):949-955.

9. Geyer PE, Wewer Albrechtsen NJ, Tyanova S, GrassI N, lepsen EW, Lundgren J, Madsbad S, Holst JJ, Torekov SS, Mann M: Proteomics reveals the effects of sustained weight loss on the human plasma proteome. Mol Syst Biol 2016, 12(12):901-901.

10. Koivula RW, Forgie IM, Kurbasic A, Viñuela A, Heggie A, Giordano GN, Hansen TH, Hudson M, Koopman $A D M$, Rutters $F$ et al: Discovery of biomarkers for glycaemic deterioration before and after the onset of type 2 diabetes: descriptive characteristics of the epidemiological studies within the IMI DIRECT Consortium. Diabetologia 2019, 62(9):1601-1615.

11. Niu L, Geyer PE, Wewer Albrechtsen NJ, Gluud LL, Santos A, Doll S, Treit PV, Holst JJ, Knop FK, Vilsbøll $\mathrm{T}$ et al: Plasma proteome profiling discovers novel proteins associated with non-alcoholic fatty liver disease. Mol Syst Biol 2019, 15(3):e8793-e8793.

12. Xu M, Deng J, Xu K, Zhu T, Han L, Yan Y, Yao D, Deng H, Wang D, Sun Y et al: In-depth serum proteomics reveals biomarkers of psoriasis severity and response to traditional Chinese medicine. Theranostics 2019, 9(9):2475-2488. 
13. Emilsson V, Ilkov M, Lamb JR, Finkel N, Gudmundsson EF, Pitts R, Hoover H, Gudmundsdottir V, Horman SR, Aspelund T et al: Co-regulatory networks of human serum proteins link genetics to disease. Science (New York, NY) 2018, 361(6404):769-773.

14. Fine MJ, Auble TE, Yealy DM, Hanusa BH, Weissfeld LA, Singer DE, Coley CM, Marrie TJ, Kapoor WN: A prediction rule to identify low-risk patients with community-acquired pneumonia. The New England journal of medicine 1997, 336(4):243-250.

15. Vincent JL, Moreno R, Takala J, Willatts S, De Mendonca A, Bruining H, Reinhart CK, Suter PM, Thijs LG: The SOFA (Sepsis-related Organ Failure Assessment) score to describe organ dysfunction/failure. On behalf of the Working Group on Sepsis-Related Problems of the European Society of Intensive Care Medicine. Intensive care medicine 1996, 22(7):707-710.

16. Yu X, Schneiderhan-Marra N, Joos TO: Protein microarrays for personalized medicine. Clin Chem 2010, 56(3):376-387.

17. Uyeki TM, Bernstein HH, Bradley JS, Englund JA, File TM, Fry AM, Gravenstein S, Hayden FG, Harper SA, Hirshon JM et al: Clinical Practice Guidelines by the Infectious Diseases Society of America: 2018 Update on Diagnosis, Treatment, Chemoprophylaxis, and Institutional Outbreak Management of Seasonal Influenzaa. Clinical infectious diseases : an official publication of the Infectious Diseases Society of America 2019, 68(6):895-902.

18. Zhong NS, Li YM, Yang ZF, Wang C, Liu YN, Li XW, Shu YL, Wang GF, Gao ZC, Deng GH et al: Chinese guidelines for diagnosis and treatment of influenza (2011). Journal of thoracic disease 2011, 3(4):274-289.

19. Reed C, Chaves SS, Perez A, D'Mello T, Daily Kirley P, Aragon D, Meek JI, Farley MM, Ryan P, Lynfield R et al: Complications among adults hospitalized with influenza: a comparison of seasonal influenza and the $2009 \mathrm{H} 1 \mathrm{~N} 1$ pandemic. Clinical infectious diseases : an official publication of the Infectious Diseases Society of America 2014, 59(2):166-174.

20. Teng F, Liu X, Guo SB, Li Z, Ji WQ, Zhang F, Zhu XM: Community-acquired bacterial co-infection predicts severity and mortality in influenza-associated pneumonia admitted patients. Journal of infection and chemotherapy : official journal of the Japan Society of Chemotherapy 2019, 25(2):129136.

21. Youssef J, Novosad SA, Winthrop KL: Infection Risk and Safety of Corticosteroid Use. Rheumatic diseases clinics of North America 2016, 42(1):157-176, ix-x.

22. Martin-Loeches I, M JS, Vincent JL, Alvarez-Lerma F, Bos LD, Sole-Violan J, Torres A, Rodriguez A: Increased incidence of co-infection in critically ill patients with influenza. Intensive care medicine 2017, 43(1):48-58.

23. Chow EJ, Doyle JD, Uyeki TM: Influenza virus-related critical illness: prevention, diagnosis, treatment. Crit Care 2019, 23(1):214-214.

24. SG M, S V, PR M, J L-B, TS AK, A AM, AP A, E A-B, C B, M B et al: Effectiveness of neuraminidase inhibitors in reducing mortality in patients admitted to hospital with influenza $A$ H1N1pdm09 virus infection: a meta-analysis of individual participant data. 2014, 2(5):395-404. 
25. Shie J-J, Fang J-M: Development of effective anti-influenza drugs: congeners and conjugates - a review. J Biomed Sci 2019, 26(1):84-84.

26. Behillil S, May F, Fourati S, Luyt C-E, Chicheportiche T, Sonneville R, Tandjaoui-Lambiotte Y, Roux D, Guérin L, Mayaux $\mathrm{J}$ et al: Oseltamivir resistance in severe influenza $\mathrm{A}(\mathrm{H} 1 \mathrm{~N} 1)$ pdm09 pneumonia and acute respiratory distress syndrome: a French multicenter observational cohort study. Clinical infectious diseases : an official publication of the Infectious Diseases Society of America 2019:ciz904.

27. Hurt AC, Kelly H: Debate Regarding Oseltamivir Use for Seasonal and Pandemic Influenza. Emerging infectious diseases 2016, 22(6):949-955.

28. Luyt CE, Rice TW: Co-infection in severe influenza: a new epidemiology? Intensive care medicine 2017, 43(1):107-109.

29. Klonoski JM, Watson T, Bickett TE, Svendsen JM, Gau TJ, Britt A, Nelson JT, Schlenker EH, Chaussee MS, Rynda-Apple A et al: Contributions of Influenza Virus Hemagglutinin and Host Immune Responses Toward the Severity of Influenza Virus: Streptococcus pyogenes Superinfections. Viral immunology 2018, 31(6):457-469.

30. Umetsu DT, Ambrosino DM, Quinti I, Siber GR, Geha RS: Recurrent sinopulmonary infection and impaired antibody response to bacterial capsular polysaccharide antigen in children with selective IgGsubclass deficiency. The New England journal of medicine 1985, 313(20):1247-1251.

31. Björkander J, Bake B, Oxelius VA, Hanson LA: Impaired lung function in patients with IgA deficiency and low levels of IgG2 or IgG3. The New England journal of medicine 1985, 313(12):720-724.

32. Shield JP, Strobel S, Levinsky RJ, Morgan G: Immunodeficiency presenting as hypergammaglobulinaemia with IgG2 subclass deficiency. Lancet (London, England) 1992, 340(8817):448-450.

33. Schauer U, Stemberg F, Rieger CH, Buttner W, Borte M, Schubert S, Mollers H, Riedel F, Herz U, Renz H et al: Levels of antibodies specific to tetanus toxoid, Haemophilus influenzae type $b$, and pneumococcal capsular polysaccharide in healthy children and adults. Clinical and diagnostic laboratory immunology 2003, 10(2):202-207.

34. Sangster MY, Riberdy JM, Gonzalez M, Topham DJ, Baumgarth N, Doherty PC: An early CD4+ T celldependent immunoglobulin A response to influenza infection in the absence of key cognate T-B interactions. The Journal of experimental medicine 2003, 198(7):1011-1021.

35. Latiff AH, Kerr MA: The clinical significance of immunoglobulin A deficiency. Annals of clinical biochemistry 2007, 44(Pt 2):131-139.

36. Collaborators GBDI: Mortality, morbidity, and hospitalisations due to influenza lower respiratory tract infections, 2017: an analysis for the Global Burden of Disease Study 2017. The Lancet Respiratory medicine 2019, 7(1):69-89.

37. Hernandez-Vargas EA, Wilk E, Canini L, Toapanta FR, Binder SC, Uvarovskii A, Ross TM, Guzmán CA, Perelson AS, Meyer-Hermann M: Effects of aging on influenza virus infection dynamics. $J$ Virol 2014, 88(8):4123-4131. 
38. Bellelli V, d'Ettorre G, Celani L, Borrazzo C, Ceccarelli G, Venditti M: Clinical significance of lymphocytopenia in patients hospitalized with pneumonia caused by influenza virus. Crit Care 2019, 23(1):330-330.

39. Hornick EE, Dagvadorj J, Zacharias ZR, Miller AM, Langlois RA, Chen P, Legge KL, Bishop GA, Sutterwala FS, Cassel SL: Dendritic cell NLRC4 regulates influenza A virus-specific CD4 T cell responses through FasL expression. J Clin Invest 2019, 129(7):2888-2897.

40. La Gruta NL, Turner SJ: T cell mediated immunity to influenza: mechanisms of viral control. Trends Immunol 2014, 35(8):396-402.

41. Lu J, Wei Z, Jiang $H$, Cheng $L$, Chen Q, Chen M, Yan J, Sun Z: Lactate dehydrogenase is associated with 28-day mortality in patients with sepsis: a retrospective observational study. J Surg Res 2018, 228:314-321.

42. Teng F, Wan TT, Guo SB, Liu X, Cai JF, Qi X, Liu WX: Outcome prediction using the Mortality in Emergency Department Sepsis score combined with procalcitonin for influenza patients. Medicina clinica 2019.

43. Hoffman W, Lakkis FG, Chalasani G: B Cells, Antibodies, and More. Clinical journal of the American Society of Nephrology : CJASN 2016, 11(1):137-154.

44. Liu WJ, Zou R, Hu Y, Zhao M, Quan C, Tan S, Luo K, Yuan J, Zheng H, Liu J et al: Clinical, immunological and bacteriological characteristics of $\mathrm{H} 7 \mathrm{~N} 9$ patients nosocomially co-infected by Acinetobacter Baumannii: a case control study. BMC infectious diseases 2018, 18(1):664.

\section{Figures}




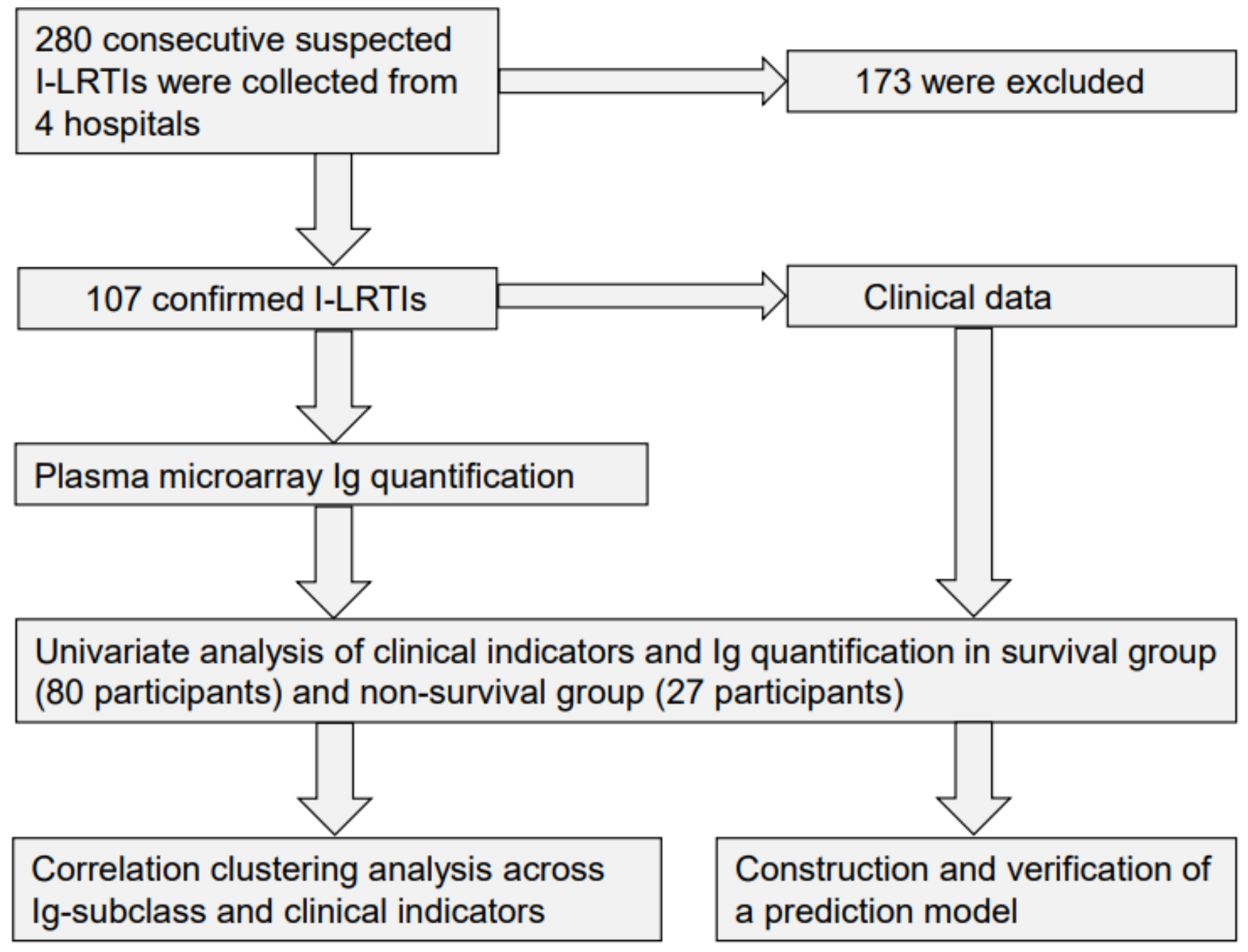

Figure 1

Flow chart. In the winter of 2018-2019, participants were selected from consecutive influenza patients who visited EDs in four teaching hospitals by pre-established inclusion criteria and exclusion criteria. When patients arrived at the EDs, the first clinical evaluation and plasma samples collection were achieved. The amount of immunoglobulin in the plasma was quantified using the standard curve generated by the purified immunoglobulin standards. According to the final prognosis, all participants were divided into a survival group and a non-survival group, and the differences of variables between the two groups were compared by univariate analysis. Variables with significant differences and marginal differences were used in correlation network analysis to observe the characteristics of the coordinated changes of indicators of the homeostasis imbalance in the non-survivors. A comprehensive correlation analysis between the immunoglobulin proteome expression and clinical data helped construct a prediction model, to distinguish patients at high risk of mortality at the ED arrival. 

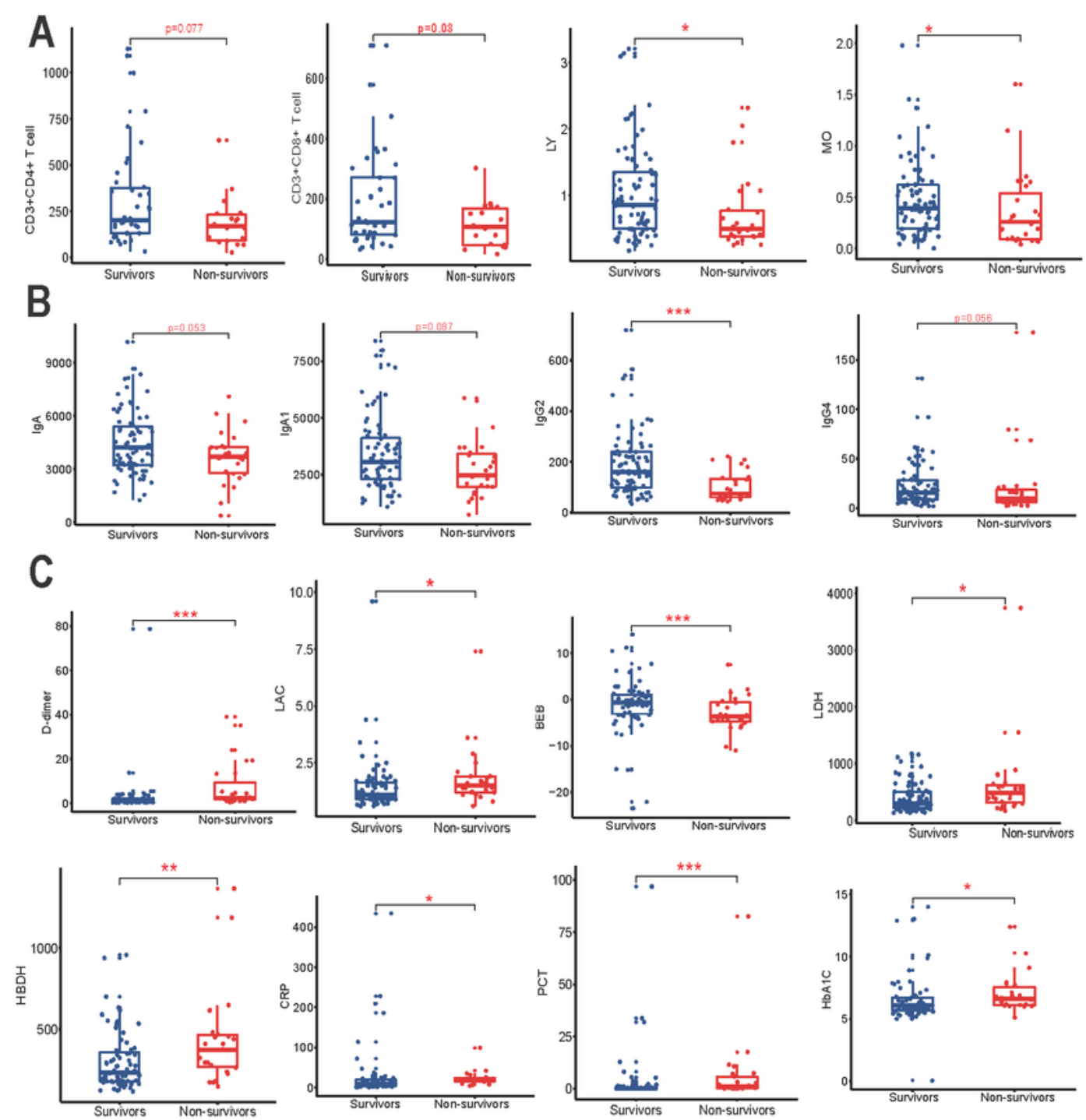

D

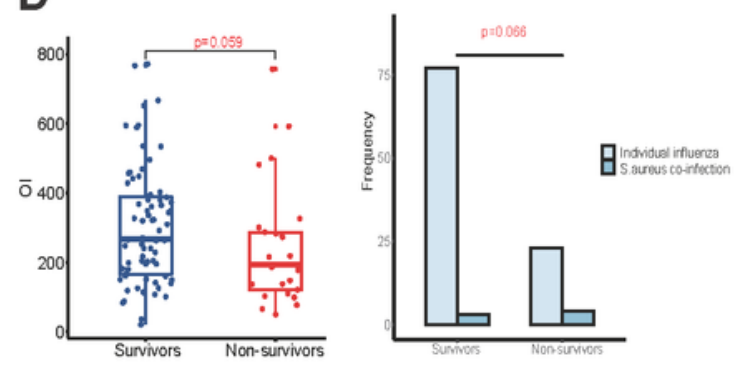

Figure 2

Univariate analysis of variables with significant statistical differences and marginal statistical differences between the survivors and non-survivors. A. Immune cells. B. Immunoglobulin and subclass. C. Biomarkers related to severe infection. D. Other clinical factors associated with prognosis. Mann Whitney $\mathrm{U}$ test was used for quantitative variables, and Fisher's accurate test was used for qualitative variables. Different statistical significance levels were marked $(p<0.001 * \star \star, p<0.01 * *, p<0.05 *, p<0.1)$. 

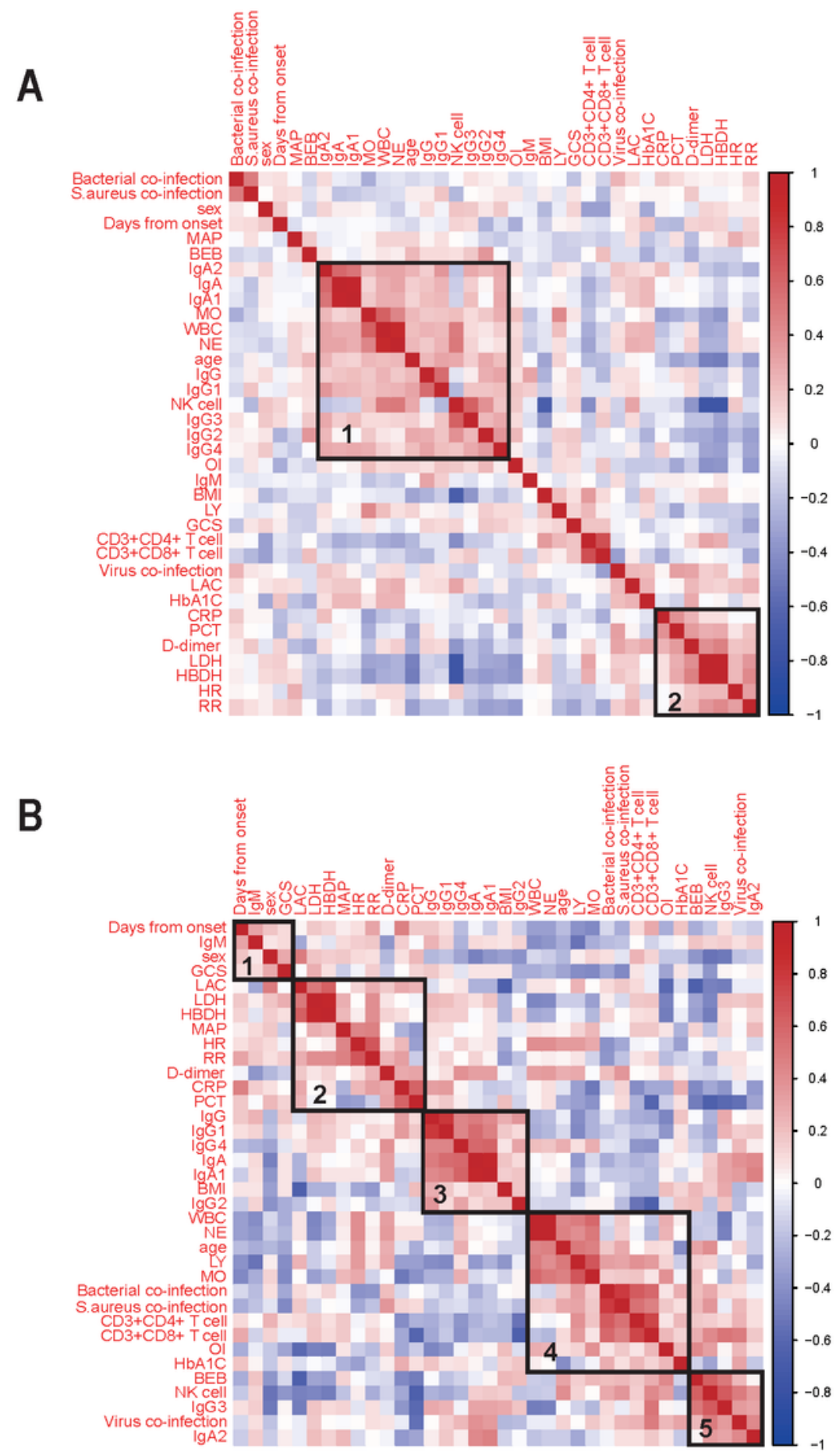

\section{Figure 3}

Construction of co-regulation networks described by hierarchical correlation clustering heatmap in the survival and non-survival groups. Spearman correlation coefficient was used to measure the correlation between the indicator pairs, and hierarchical clustering was used to cluster the highly correlated clinical indicators into modules. Red color represents a positive correlation, blue color represents a negative correlation, and the brighter the color, the stronger the correlation. A. Different variables were respectively 
clustered into two red modules with boundary. Cluster 1 contained IgA, IgA1-2, IgG, IgG1-4, WBC, NE, MO, NK cell, and age. Cluster 2 contained CRP, PCT, D-dimer, LDH, LBDH, HR and RR. B. Different variables were respectively clustered into five red modules with boundary. Cluster 1 contained days from onset to ED, IgM, sex, and GCS. Cluster 2 contained LAC, LDH, HBDH, MAP, HR, RR, D-dimer, CRP and PCT. Cluster 3 contained IgA, IgA1, IgG, IgG1, IgG2, IgG4 and BMI. Cluster 4 contained age, WBC, NE, MO, LY, CD3+CD4+Tcell, and CD3+CD8+T-cell, OI, HbA1C and bacterial co-infection. Cluster 5 contained NK cell, IgG3, IgA2, BEB and virus co-infection.

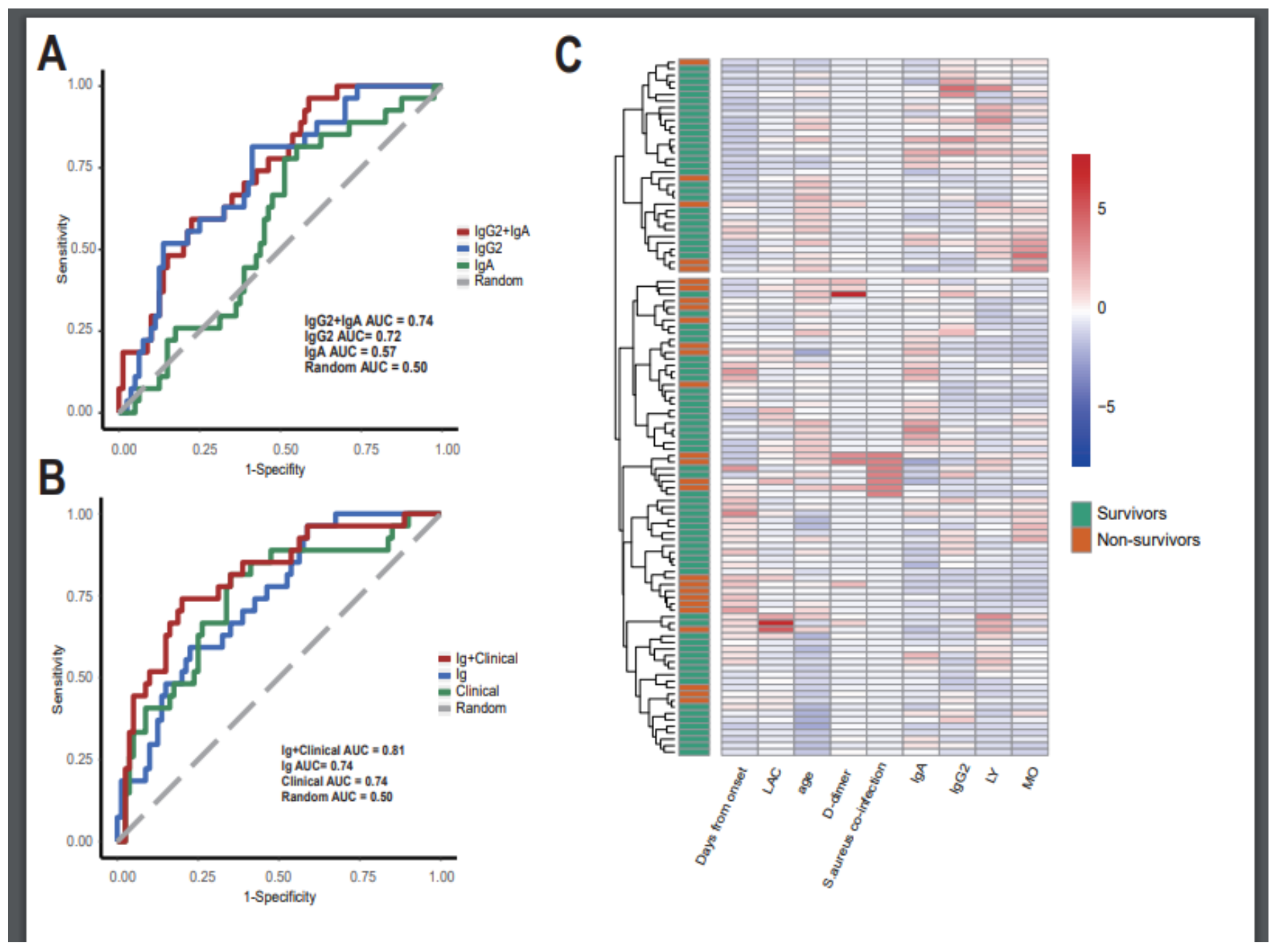

Figure 4

A. Receiver operating characteristic curves of prediction for prognosis of immunoglobulin based on multivariate Logistic regression. The blue line represented IgG2. The green line represented represented IgA. The red line represented the combination of immunoglobulin quantification (including IgA and IgG2). B. Receiver operating characteristic curves of prediction model based on multivariate Logistic regression. The blue line represented the combination of immunoglobulin quantification (including $\lg A$ and $\lg G 2$ ). The green line represented the combination of clinical indicators (including D-dimer, Days from onset to ED, LAC, LY, MO, S.aureus co-infection and age). The red line represented the combination of immunoglobulin 
quantification and clinical indicators (including D-dimer, Days from onset to ED, IgA, IgG2, LAC, LY, MO, S. aureus co-infection and age). C. Participants - indexes hierarchical correlation clustering heatmap of composite features based on immunoglobulin quantification and clinical indicators (including D-dimer, Days from onset to ED, IgA, IgG2, LAC, LY, MO, S.aureus co-infection and age). Columns were indexes characteristics and rows were participants.

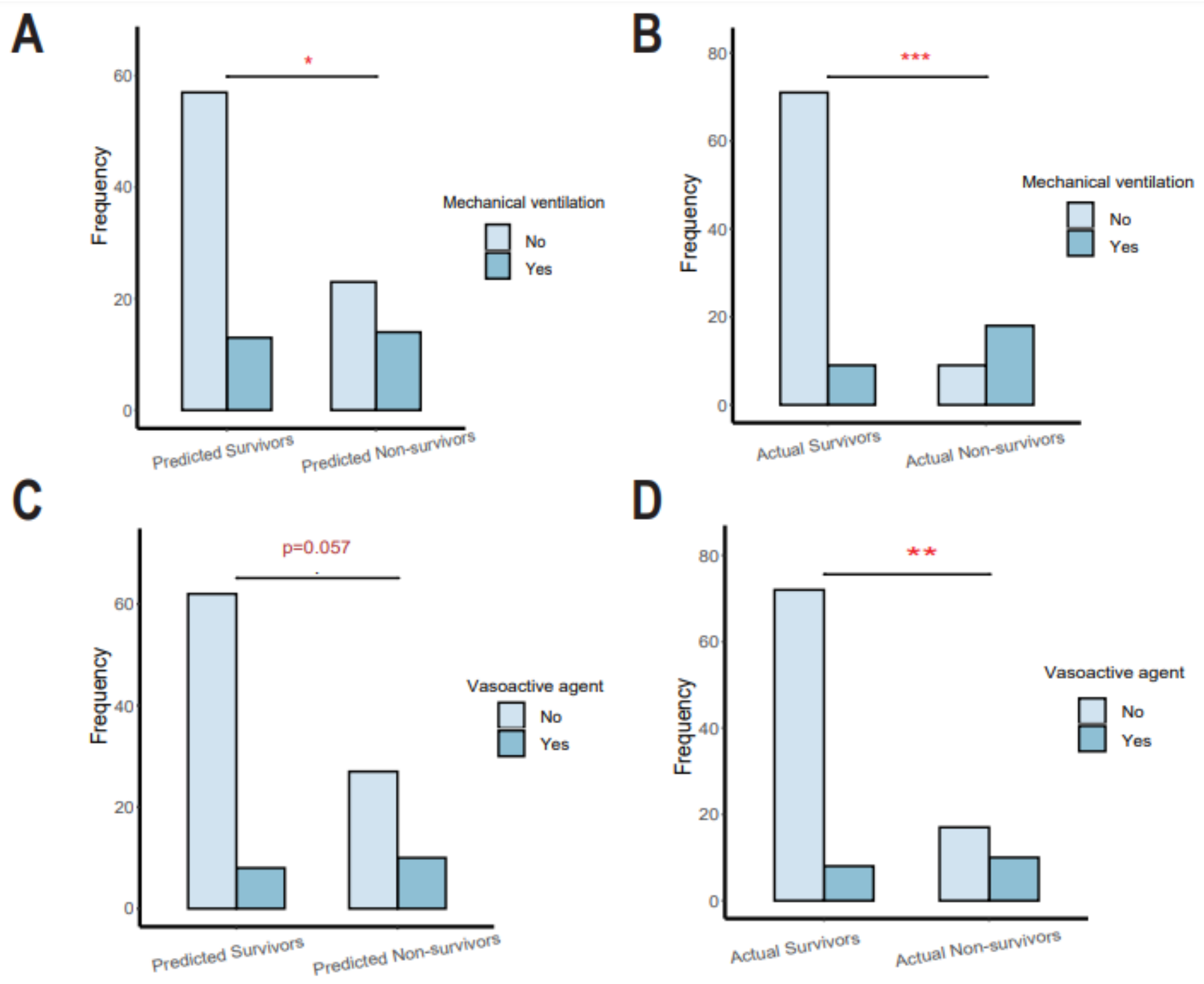

\section{Figure 5}

The efficacy of the model in predicting critical condition (mechanical ventilation and vasoactive agents). Fisher's accurate test was used to calculate the $p$ value, and different statistical significance levels were noted $(p<0.001 * * *, p<0.01 * *, p<0.05 *, p<0.1)$. 